\title{
水培经济植物对酿酒废水净化与 资源化生态工程研究*
}

\author{
戴全裕 陈源高 魏 云 \\ (中国科学院南京地理与湖泊研究所, 南京 210008) \\ 张 班 戴玉兰 蒋兴昌 $* *$ \\ (无锡市电影胶片厂环保科, 无锡 214165)
}

70 年代前, 国内外利用水生高等植物来净化处理污水, 常常选用的生物材料是一般水生 杂草(如凤眼莲 Eichhornia crassipes Solms. 喜旱莲子草 Alternanthera philoixeroides Griseb. 和宽叶香蒲 Typha latifolia L. 等 $)^{[1,2]}$. 虽然它们都有一定的净化能力, 有的可以做饲料、肥料 或燃料, 但是总起来说, 经济效益不高, 还存在着冬季净化问题和二次污染问题, 因而限制了 它的广泛应用. 然而, 到了 80 年代就有学者开始对湖泊或污染水体进行陆生经济植物的无土 栽培研究 ${ }^{[3 ~ 89}$. 但是至今尚末见到以陆生经济植物为主体的酿酒废水净化与资源化生态工程 研究的报道. 而本文在前人工作的基础上,于 $1991 \sim 1993$ 年在无锡市酿酒总厂内, 利用酿酒 废水 (啤酒废水和黄酒废水), 不仅水培了丝瓜 (Luffa cylindrica Roem.)、水芹菜 (Oenanthe javanica DC.)、水䔨菜 (Ipomoea aquatica Forsk.)、西洋菜 (Nasturtium officinale R. Br.) 和 金针菜 (Hemerocallis fulva L.) 等多种经济植物 (包括蔬菜和花卉), 而且在 1.344 ha 氧化圹水 面上建立了以水培经济植物为主的酿酒废水净化与资源化生态工程新体系. 并且得到了较好 的环境效益、经济效益和生态效益. 采用水培经济植物为主的生态工程优点是：1) 经济效益 高；2) 植物的净化周期长；3)二次污染少；4) 水培的花卉可以美化水面环境等. 因此, 该项 研究不仅具有重要的科学意义, 而且也具有较大的实际应用价值. 从而为无毒有机废水资源 化开辟了一条新路.

\section{1 实验材料与方法}

\section{1 水培经济植物的篣选}

经过篮选而用于实验的经济植物品种有: 绿色蔬菜类 10 种; 花卉类 5 种 (金针菜、莲藉 既是蔬菜类, 也是花卉类); 粮食作物 1 种. 另外还有饲草类 2 种. 若按植物对温度的适应性 来区分, 则喜温植物有 11 种, 耐寒植物有 5 种. 篮选耐寒植物有利于延长植物对污水的净化 期 (见表 1). 由于工厂废水有余热, 如果在水面上再有塑料薄膜复盖 (载体上盖薄膜), 则基本 上可以做到周年运转.

1995-04-13 收稿, 1995-07-25 收修改稿

*国家自然科学基金和中国科学院南京分院基金资助项目

** 江南大学应用化学系 
表 1 不同经济植物对污水的净化期 a)

\begin{tabular}{|c|c|c|c|c|c|c|c|c|c|c|c|c|}
\hline \multirow{2}{*}{ 植物名 称 } & \multicolumn{12}{|c|}{ 份 } \\
\hline & 1 & 2 & 3 & 4 & 5 & 6 & 7 & 8 & 9 & 10 & 11 & 12 \\
\hline 1 喜温植物 & & $\cdot$ & & & & & & & & & & \\
\hline 水猚莱 (Ipomoea aquatica) & & & & & & & & & & - & & \\
\hline 丝 瓜(Luffa cylindrica) & & & & & & & & & & & & \\
\hline 金针㨀 (Hemerocallis fulva) & & & & & & & & & & & & \\
\hline 慈 菇(Sagittaria sagittifolia) & & & & & & & & & & & & \\
\hline 菨 白(Zizania latifolia) & & & & & & & & & & & & \\
\hline 水 稻 (Oryza sativa) & & & & & & & & & & - & & \\
\hline 莲 藕 (Nelumbo nucifera) & & & & & & & & & & & & \\
\hline 等 尾(Iris tectorum) & & & & & & & & & & & 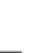 & \\
\hline 半枝莲 (Portulaca grandiflora) & & & & & & & & & & & - & \\
\hline $\begin{array}{l}\text { 红睡蓬 (Nymphaea lotus) } \\
\text { 凤眼莲 (Eichomia crassipes) }\end{array}$ & & & & & & & & & & & & \\
\hline 2 利寒植物 & & & & & & & & & & & & \\
\hline 西洋菜 (Nasturtium officinale) & & & & & & & & & & & & $--\ldots$ \\
\hline 水芹菜 (Oenanthe javanica) & & & & & & & & & _ & & & $\ldots$ \\
\hline 大 蒜(Allium sativum) & & & & & & & - & & 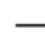 & & & \\
\hline 香 葱 (Allium fistulosum) & & & & & & & - & & - & & & - \\
\hline 多花黑麦草(Lolium multiflonum) & & & & & & - & & & & & & --- \\
\hline
\end{tabular}

a) 为长江以南地区净化期, - - - 表示有薄膜等保温措施

\section{2 水面载体的设计与选择}

因为大多数水培经济植物不能在水面上直立生长, 故水面飘浮式载体的设计和材料的选 择是必须的. 不同的经济植物因形态结构和生物学特性的不同而需要不同的载体. 为此设计 了多种类型的载体, 其中以毛竹载体和泡沫塑料载体的运用较广, 且经久耐用, 成本较低 (见 图 1,2).

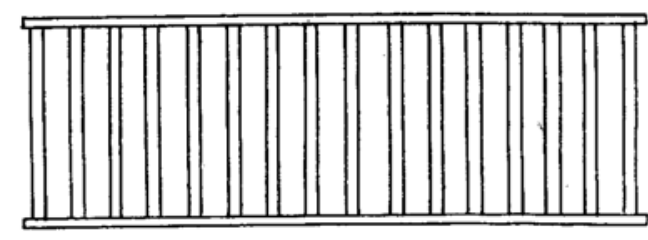

图 1 聚浮式毛竹载体

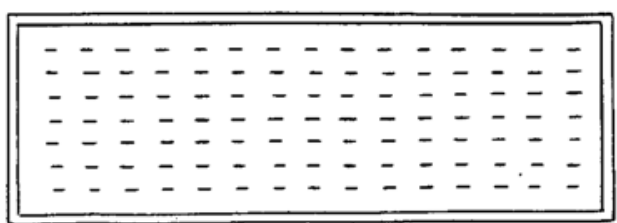

图 2 飘浮式泡沫塑料辀体

\section{3 实验方法}

本项研究分静态试验和示范生态工程试验 (实际应用) 两部分, 示范生态工程试验方法将 在后面论述.

静态试验的方法是：在植物篣选培养的基础上,我们做了 16 种不同种类的植物净化率(见 表 1). 首先选用若干清洁的塑料大盆 (直径 $50 \mathrm{~cm}$, 高 $20 \mathrm{~cm}$ ), 分别加人 $15 \mathrm{~kg}$ 酿酒废水, 然 后将预先培养好的试验植物, 小心地用去离子水清洗干净 (切勿损伤根系). 称取一定量的植 物样, 分别放人塑料大盆中, 其中一只不放植物作对照, 在不同时间内测定污染物浓度的变 化. 试验均在自然光照下进行, 实验时间为 $120 \mathrm{~h}$. 
测定的项目有：气温、水温、 $\mathrm{pH}$ 、浊度、 $\mathrm{TN}, \mathrm{TP}, \mathrm{NH}_{4}^{+}-\mathrm{N}, \mathrm{COD}_{\mathrm{cr}}$ 重金属以及植物的生长 状况等.

\section{2 结果与讨论}

\section{1 水培经济植物在静态试验中对酿酒废水的净化能力}

静态试验结果表明, 水培经济植物对酿酒废水都有较好的净化能力. 现以丝瓜、萃白、水 䔨菜、水芹菜和西洋菜为例, 当污水停留时间为 $120 \mathrm{~h}$ 时, 它们对废水中污染物的去除率可 达: TN $89.0 \% \sim 95.9 \%$; TP $81.3 \% \sim 98.6 \%$; $\mathrm{NH}_{4}^{+}-\mathrm{N} 93.9 \% \sim 99.6 \%$ 和 $\mathrm{COD}_{\mathrm{cr}}$ $35.6 \% \sim 87.4 \%$. 其中对 $\mathrm{COD}_{\mathrm{cr}}$ 的去除率较差些. 根据污染物去除负荷的计算,则丝瓜每天 每 $\mathrm{kg}$ 植物体(鲜重) 可以去除啤酒废水中 TN $107.28 \mathrm{mg}, \mathrm{TP} 18.96 \mathrm{mg}, \mathrm{NH}_{4}^{+}-\mathrm{N} 75.84 \mathrm{mg}$ 和 $\mathrm{COD}_{\mathrm{cr}} 940.1 \mathrm{mg}$; 水芹菜每天每公斤植物体可以去除黄酒废水中 TN $35.78 \mathrm{mg}$, TP $4.18 \mathrm{mg}, \mathrm{NH}_{4}^{+}-\mathrm{N} 20.87 \mathrm{mg}$ 和 $\mathrm{COD}_{\mathrm{cr}} 288.8 \mathrm{mg}$. 而与同期试验的饲草植物相比, 则凤眼莲每 天每公斤植物体去除啤酒废水中 TN $45.14 \mathrm{mg}, \mathrm{TP} 7.64 \mathrm{mg}, \mathrm{NH}_{4}^{+}-\mathrm{N} 11.57 \mathrm{mg}$ 和 $\mathrm{COD}_{\mathrm{cr}}$ $320.9 \mathrm{mg}$; 多花黑麦草对啤酒废水中 TN 的去除负荷为 $20.03 \mathrm{mg} / \mathrm{kg} \cdot \mathrm{d}, \mathrm{TP} 3.56 \mathrm{mg} / \mathrm{kg} \cdot \mathrm{d}$, $\mathrm{NH}_{4}^{+}-\mathrm{N} 5.34 \mathrm{mg} / \mathrm{kg} \cdot \mathrm{d}$ 和 $\mathrm{COD}_{\mathrm{cr}} 147.5 \mathrm{mg} / \mathrm{kg} \cdot \mathrm{d}$. 其中丝瓜的去除负荷可以与凤眼莲相㜅 美 (见表 2，3).

表 2 水培经济植物对黄酒废水的净化能力 $(120 \mathrm{~h})$

\begin{tabular}{|c|c|c|c|c|c|c|c|c|c|c|}
\hline \multirow{2}{*}{ 项 } & \multirow{2}{*}{$\begin{array}{c}\text { 废水最/ } \\
\text { kg }\end{array}$} & \multirow{2}{*}{$\begin{array}{c}\text { 植物暗/ } \\
\mathrm{kg}\end{array}$} & \multicolumn{2}{|c|}{$\mathrm{TN}$} & \multicolumn{2}{|l|}{ TP } & \multicolumn{2}{|c|}{$\mathrm{NH}_{4}^{+}-\mathrm{N}$} & \multicolumn{2}{|c|}{$\mathrm{COD}_{\sigma}$} \\
\hline & & & $\mathrm{mg} \cdot \mathrm{L}^{-1}$, & $R / \%$ & $\mathrm{mg} \cdot \mathrm{L}^{-1}$, & $R / \%$ & $\mathrm{mg} \cdot \mathrm{L}^{-1}$, & $R / \%$ & $\mathrm{mg} \cdot \mathrm{L}^{-1}$ & $R / \%$ \\
\hline 起始浓度 & & & 49.26 & & 4.44 & & 34.12 & & 387.1 & \\
\hline 对照组 & 15.0 & - & 21.76 & 55.8 & 3.09 & 30.4 & 13.35 & 60.9 & 232.2 & 40.0 \\
\hline 试验组 & & & & & & & & & & \\
\hline 水芹菜 & 15.0 & 1.62 & 2.44 & 95.0 & 0.83 & 81.3 & 2.08 & 93.9 & 76.2 & 80.3 \\
\hline 西洋莱 & 15.0 & 2.24 & 3.42 & 93.1 & 0.26 & 94.1 & 0.619 & 98.2 & 48.8 & 87.4 \\
\hline
\end{tabular}

表 3 水培经济植物对啤酒废水的净化能力 $(120 \mathrm{~h})$

\begin{tabular}{|c|c|c|c|c|c|c|c|c|c|c|}
\hline \multirow{2}{*}{ 项 目 } & \multirow{2}{*}{$\begin{array}{c}\text { 废水量/ } \\
\mathrm{kg}\end{array}$} & \multirow{2}{*}{$\begin{array}{l}\text { 植物量/ } \\
\text { kg }\end{array}$} & \multicolumn{2}{|c|}{$\overline{\mathrm{TN}}$} & \multicolumn{2}{|l|}{ TP } & \multicolumn{2}{|c|}{$\mathrm{NH}_{4}^{+}-\mathrm{N}$} & \multicolumn{2}{|c|}{$\mathrm{COD}_{\alpha}$} \\
\hline & & & $\mathrm{mg} \cdot \mathrm{L}^{-1}$, & $R / \%$ & $\mathrm{mg} \cdot \mathrm{L}^{-1}$, & $R / \%$ & $\mathrm{mg} \cdot \mathrm{L}^{-1}$, & $R / \%$ & $\mathrm{mg} \cdot \mathrm{L}^{-1}$ & $R / \%$ \\
\hline 起始浓度 & & & 47.21 & & 5.63 & & 25.14 & & 118.7 & \\
\hline 对照组 & 15.0 & - & 12.00 & 74.6 & 1.13 & 79.9 & 2.98 & 88.1 & $144^{2)}$ & -21.3 \\
\hline 试验组 & & & & & & & & & & \\
\hline 丝 瓜 & 15.0 & 0.39 & 5.17 & 89.0 & 0.54 & 90.4 & 0.21 & 99.2 & 66.4 & 44.1 \\
\hline 荠 白 & 15.0 & 1.31 & 4.78 & 90.0 & 1.01 & 82.1 & 0.60 & 97.6 & 76.5 & 35.6 \\
\hline 水葋菜 & 15.0 & 0.92 & 1.95 & 95.9 & 0.08 & 98.6 & 0.11 & 99.6 & 31.5 & 73.5 \\
\hline
\end{tabular}

a) 莱类恶性繁殖影响

\section{2 酿酒废水净化与资源化示范生态工程}

\subsection{1 示范生态工程的设计}

该项研究在无锡市酿酒总厂内进行. 该厂位于无锡市 (太湖西侧) 马山地区. 1991 1993 年啤酒生产总量为 $1.5 \sim 1.8$ 万 $\mathrm{t} / \mathrm{a}$, 黄酒 $5000 \mathrm{t} / \mathrm{a}$. 日排废水量约 $1500 \mathrm{t}$. 虽然酿酒废 水经二级生化曝气处理, 但是在排放废水中, 营养物质仍然较高, 而对周围环境产生了一定的 
影响.

为了对该厂酿酒废水进行深度处理以及综合开发利用, 我们采取了以水培经济植物为主要 生物材料, 并与养鱼、养猪等配套技术相结合, 将原有 $1.344 \mathrm{ha}$ 的氧化圹划分为三个功能 区: 即经济植物净化区、养鱼区和莲藕区, 然后出水. 各区的布局如下:

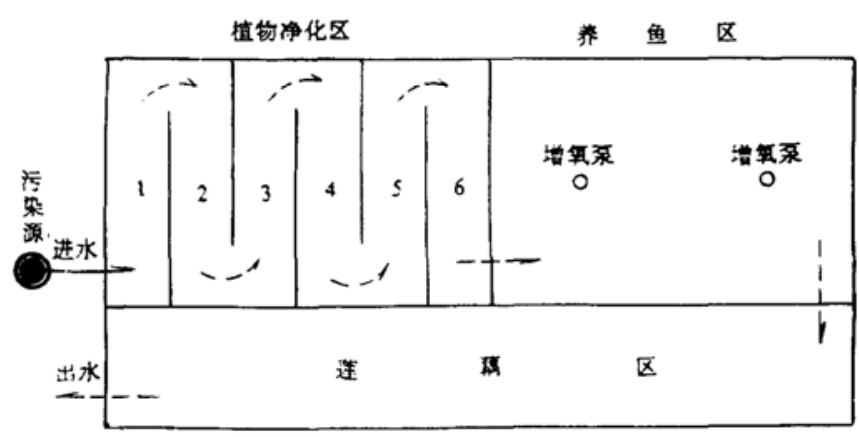

图 3 水培经济植物对酿酒废水的净化处理生态工程结构图

1 凤眼莲, 2 萃白, 3 丝瓜, 4.5 水䔨菜, 6 凤眼莲

(1)植物净化区：面积 $0.448 \mathrm{ha}$. 石堤, 中间有 5 条隔墙,水成“之”字形流动. 平均水深 $2.0 \mathrm{~m}$, 污水停留时间为 $6 \mathrm{~d}$. 在此区域内, 第 1 级种植了凤眼莲 (因废水浓度较高), 面积为 $0.075 \mathrm{ha}$. 正常生长时风眼莲的平均密度为 58 株 $/ \mathrm{m}^{2}$, 平均生物量为 $32.7 \mathrm{~kg} / \mathrm{m}^{2}$; 第 2 级, 面积 同上, 水培了艾白, 复盖水面 $1 / 2$, 植株高度达 $1.2 \mathrm{~m}$ 以上; 第 3 级,面积同上,水培了丝瓜 (需 要在水面上搭棚架), 复盖水面 $2 / 3$, 生长正常, 在 $5 \mathrm{~d}$ 内茎蔓平均增长 $71.5 \mathrm{~cm}$, 最大者可达 $87.6 \mathrm{~cm}$, 根系 $5 \mathrm{~d}$ 内平均生长 $67.45 \mathrm{~cm}$, 最长达 $95.6 \mathrm{~cm}$; 第 4 和第 5 级, 面积为 $0.149 \mathrm{ha}$, 栽培 了水䔨菜, 各占水面积 $1 / 2$ (因要空出航道). 䔨菜长势旺盛, 根系发达, $10 \sim 15 \mathrm{~d}$ 收割 1 次, 而 每次平均生物量为 $2.5 \mathrm{~kg} / \mathrm{m}^{2}$ (茎叶食用部分); 第 6 级种植风眼莲, 面积为 $0.075 \mathrm{ha}$, 平均密度 为 112 株 $/ \mathrm{m}^{2}$, 平均生物量为 $21.7 \mathrm{~kg} / \mathrm{m}^{2}$, 并且定期不断地打捞, 用于喂猪和奶牛等. 在该区还 水培了一些其它经济植物, 如水稻、慈菇、金针菜等, 不过它们所占的水面每种只有几平方米至 10 多平方米. 在冬季, 则采用耐寒性较强的水培经济植物, 如水芹菜、西洋菜、大蒜和香苟等 （水芹菜栽培了 $0.225 \mathrm{ha}$, 其它合计 $0.075 \mathrm{ha}$ ), 其中水芹菜的平均生物量为 $10.5 \mathrm{~kg} / \mathrm{m}^{2}$, 在适 宜温度下的倍增时间为 $10 \sim 15 \mathrm{~d}$.

(2) 养鱼区: 面积 0.448 ha. 平均水深 $1.5 \mathrm{~m}$. 由于该区原来水质发黑、发真, 无法用于养 鱼或作他用. 然而, 自从前级布设了以水培经济植物为主的植物净化区后, 使其水质大有改 善, 基本上达到了养鱼水质标准. 1992 年共放养鱼种 600 余 $\mathrm{kg}$, 结果未出现大批死鱼现象, 最 后鱼产量达 $5625 \mathrm{~kg} / \mathrm{ha}$.

(3) 莲藕区的目的是进一步净化养鱼污水, 同时底泥也得到了一定的净化. 该区的面积为 0.488 ha. 栽种莲藕种 $127.4 \mathrm{~kg}$. 结果莲耦长势旺盛, 荷花歌香, 从而使氧化圹面貌大为改 观.

\subsection{2 示范生态工程的环境效益}

根据 1992 年实际的运转情况看, 其环境效益是显著的. 经测定, 经济植物区对酿酒废水 
的平均净化率为: $\mathrm{TN} 75.59 \%, \mathrm{TP} 71.84 \%, \mathrm{NH}_{4}^{+}-\mathrm{N} 83.65 \%, \mathrm{COD}_{\mathrm{cr}} 46.41 \%$ 和 浊度 $80.91 \%$ (见表 3). 使原来不能养鱼的氧化圹, 变成了可以养鱼. 并且使最终出水 TN 浓度降 至为 $2.08 \mathrm{mg} / \mathrm{L}$. TP $0.223 \mathrm{mg} / \mathrm{L}, \mathrm{NH}_{4}^{+}-\mathrm{N} 0.763 \mathrm{mg} / \mathrm{L}$ 和 $\mathrm{COD}_{\mathrm{cr}} 38.98 \mathrm{mg} / \mathrm{L}$. 其水质透明度 也大大提高, 最后出水的浊度仅为 $8^{\circ}$, 达到了酿酒废水深度处理的目的.

表 4 经济植物净化区水质

\begin{tabular}{cccccc}
\hline 百 & \multicolumn{2}{c}{ 进 水 } & 出 & 水 & 平均去除率 $/ \%$ \\
\hline $\mathrm{TN} / \mathrm{mg} \cdot \mathrm{L}^{-1}$ & $5.823 \sim 53.770$ & 23.480 & $3.145 \sim 11.532$ & 5.731 & 75.59 \\
$\mathrm{TP} / \mathrm{mg} \cdot \mathrm{L}^{-1}$ & $2.581 \sim 4.442$ & 3.740 & $1.734 \sim 3.516$ & 1.053 & 71.84 \\
$\mathrm{NH}{ }_{4}^{+}-\mathrm{N} / \mathrm{mg} \cdot \mathrm{L}^{-1}$ & $5.602 \sim 24.758$ & 14.901 & $1.525 \sim 2.565$ & 2.436 & 83.65 \\
$\mathrm{COD} / \mathrm{mg} \cdot \mathrm{L}^{-1}$ & $77.09 \sim 250.38$ & 104.38 & $67.23 \sim 97.69$ & 55.94 & 46.41 \\
浊度 $/\left(^{\circ}\right) \cdot \mathrm{L}^{-1}$ & $73 \sim 92$ & 55 & $8.4 \sim 14$ & 10.5 & 80.91 \\
\hline
\end{tabular}

\subsection{3 示范生态工程的经济效益}

采用以经济植物为主体的污水资源化生态工程有较好的经济效益. 据统计, 在无锡市酿 酒总厂氧化圹内, 1992 年收获水培的绿色蔬菜 $17920 \mathrm{~kg}$, 价值 17920 无, 鲜藕 $5880 \mathrm{~kg}$, 价值 9408 元, 莲籽 $336 \mathrm{~kg}$, 价值 6720 元, 鲜鱼 $2520 \mathrm{~kg}$, 价值 15120 元, 青饲料 35 万 $\mathrm{kg}$, 价值 7000 元, 合计 5.62 万元, 其中投人的成本为: 材料费 3300 元, 劳力费 7200 元, 种苗费 (菜、 鱼、藕等) 8200 元, 合计 1.87 万元. 其经济效益约为 2.79 万元/ha, 效益还将会逐年增高. 由此 可见,该项研究的经济效果是显著的. 它不仅适用于酿酒废水, 而且也适合于其它无毒有机废 水应用.

\section{参考文軒}

1 Wolverton B C. Water hyacinth and alligator weeds for removal of silver, cobalt and strontium from polluted waters. NASA Tech Meme, 1975, TM-X-72 727

2 丁树荣. 高产水生维管束植物在城镇污水资源化中的作用及其发展前景. 中国环境科学, 1984, 4(2): 10 15

3 李止正, 黄国宏, 倪晋山.太湖大水面无土栽培高等陆生植物研究. 植物学报, 1991, 33(8): 614 620

4 程树培, 丁树荣, 胡志明. 利用人工基质无土栽培水䔨莱净化樂丝泼水研究. 环境科学, 1991, 12(4): 47 51

5 丁树荣, 程树培, 胡志明. 利用人工基质无土栽培多花黑麦草净化缫丝废水的研究. 中国环境科学, 1992, 12(1):9 15

6 皮 宇, 戴全裕, 陈源高. 水䔨菜 (Ipomoea aquatica) 对含银废水的净化功能研究. 植物生态学与地植物学学报, 1992, 16(2): $167 \sim 173$

7 皮 宇, 陈志强, 戴全裕. 水芹菜对含银废水的净化功能. 城市环境与城市生态, 1991, 4(1): 15 20

8 Dai Q Y, Chen Y G, Zhou W P et al. Studies on the porification of silver-containing wastewater and the reclamation of silver by water hyacinth and other aquatic plants. Chinese Scienœ Bulletin, 1992, 37(12): $1028 \sim 1032$ 